approaches. Moyamoya is treated with surgical revascularization. AIS with sickle cell disease requires urgent erythrocyte exchange transfusion to reduce hemoglobin $\mathrm{S}$ levels to less than $30 \%$ and increase hemoglobin to $10-12 \mathrm{gm} / \mathrm{dl}$. For primary prevention of AIS in sickle cell disease, patients older than 2 years are screened yearly with transcranial Doppler and placed on chronic transfusion regimen if found to have increased velocity of blood flow due to arterial narrowing. Multicenter cohort studies of acute, preventive and rehabilitation therapies are essential to establish evidence-based guidelines for treatment of AIS in childhood. (Bernard TJ, Goldenberg NA, Armstrong-Wells J, Amlie-Lefond C, Fullerton HJ. Treatment of childhood arterial ischemic stroke. Ann Neurol June 2008;63:679-696). (Respond: Dr Bernard, The Children's Hospital, Denver, CO 80045. E-mail: timothy. bernard(ciuchsc.edu).

COMMENT. Risk factors for arterial ischemic stroke in childhood are different from those in adults and include cerebral arteriopathies, vascular anomalies, congenital heart disease, infection (herpes zoster virus and varicella), head and neck trauma, sickle cell anemia, genetic/metabolic disease, and prothrombotic abnormalities. A mortality rate of 2$11 \%$ and persistent neurologic deficit in $68-73 \%$ are cited. Among the risk factors for AIS in childhood, infections and inflammatory disorders are relatively common, occurring in $27 \%$ to $34 \%$ in 2 large patient cohorts (Lee YY et al. Brain Dev 2008;30:14-19; Riikonen R et al. Neuropediatrics 1994;25:227-233). In a review of recent developments in childhood AIS, Amlie-Lefond C et al (Lancet Neurol 2008;7:425-435) stress the role of infection, the association of arteriopathy and varicella, and research in the use of antiviral, antibacterial, and anti-inflammatory therapy for AIS.

\title{
HYPOTHYROIDISM AND STURGE-WEBER SYNDROME
}

Two children out of $83(2.4 \%)$ with Sturge-Weber syndrome, who attended a multidisciplinary center at Johns Hopkins Hospital, Baltimore, MD, were found to have central hypothyroidism. The prevalence of hypothyroidism was 500-10,000 times that in the general population. Both patients (ages 7 and 12 years) received carbamazepine or oxcarbazepine for seizures, anticonvulsants known to cause abnormal thyroid function. Six $(7.2 \%)$ of the 83 reported maternal hypothyroidism. An admitted limitation of the study was the lack of routine thyroid function studies during the study period of 2000-2007, leading to a posible underestimate of thyroid dysfunction. The 2 patients tested had clinical symptoms or signs of hypothyroidism and a family history of hypothyroidism. Thyroid function tests revealed a low free thyroxine and normal TSH. Months after initiation of levothyroxine, free thyroxine level returned to normal, skin, hair loss, and energy levels improved, headaches and recurrence of stroke-like episodes resolved, but the frequency and severity of seizures were unchanged. Evaluation of possible growth-hormone deficiency is planned following linear growth deceleration. (Comi AM, Bellamkonda S, Ferene LM, Cohen BA, GermainLee EL. Central hypothyroidism and Sturge-Weber syndrome. Pediatr Neurol July 2008;39:58-62). (Respond: Dr Comi, Department of Neurology, Kennedy Krieger Institute,

707 North Broadway, Tower 100A, Baltimore, MD 21205. E-mail: comictkennedykrieger.org). 
COMMENT. These authors and associates recently described an increased prevalence of growth-hormone deficiency in patients with Sturge-Weber syndrome, 18-fold higher than in the general population (Miller RS et al. Arch Dis Child 2006;91:340-341). On the basis of their current report of central hypothyroidism in $2.4 \%$ of cases, they recommend routine thyroid-function studies in patients with Sturge-Weber syndrome.

Russell and Rubinstein, in their Pathology of Tumors of the Nervous System (London, Arnold, 1959:72-92) classify cerebral vascular malformations in four groups: arteriovenous malformations, cavernous malformations, capillary telangiectases, and venous malformations. Sturge-Weber leptomeningeal angiomatosis (capillary angioma; telangiectasia) is mainly admixed with a venous malformation; cortical calcifications are found beneath the vascular malformation or localized to cortical tissue around the walls of smaller blood vessels (Wohlwill FJ, Yakovlev PI. Histopathology of meningo-facial angiomatosis (Sturge-Weber disease). J Neuropathol Exp Neurol 1957;16:341).

Cavernous angiomas, typically located in the cerebral hemispheres, involving the Rolandic region, are uncommon in childhood but are responsible for $12 \%$ of intracranial hemorrhages due to vascular malformations (Menkes JH. Textbook of Child Neurology. Philadelphia, Lea \& Febiger, $3^{\text {rd }}$ ed. 1980;598-607). The definition of cerebral cavernous malformations (CCM) is discussed in light of histopathological findings in 87 patients treated surgically at the Medical University of Vienna, Austria (Frischer JM, et al. J Neurol Neurosurg Psychiatry July 2008;79:783-788). CCM is currently defined as a mulberry-like assembly of thin walled vascular sinusoids lined by a thin endothelium, with no intervening brain parenchyma, and surrounded by hemosiderin deposits and gliosis. These authors found intervening brain parenchyma between vessels in $70 \%$ of otherwise typical specimens, and they suggest a modification of the definition of CCM.

\section{BRAIN TUMORS AND MALFORMATIONS}

\section{LONG-TERM OUTCOME OF INFANTILE BRAIN TUMORS}

Twenty seven consecutive patients diagnosed with brain tumor in the first year of life, between 1980 and 2005, were followed at the University Children's Hospital of Zurich, Switzerland. Of 11 survivors at mean follow-up of 12.3 years, 9 had persistent neurological complications, 4 had endocrine and growth complications, and 8 had cognitive deficits with school problems and poor occupation choices. Behavioral and psychological problems occurred in 7 patients, and health-related quality of life, especially social functioning, was generally impaired. Patients with high-grade tumor histology and intense therapy had the lowest quality of life. (Gerber NU, Zehnder D, Zuzak TJ, Poretti A, Boltshauser E, Grotzer MA. Outcome in children with brain tumors diagnosed in the first year of life: long-term complications and quality of life. Arch Dis Child July 2008;93:582-589). (Respond: Dr Michael A Grotzer, University Children's Hospital, Steinweisstrasse 75, CH-8032 Zurich, Switzerland. E-mail: michael.grotzer(akispi.uzh.ch).

COMMENT. With long-term survival, the importance of quality of life issues is increased and requires early intervention. Children with brain tumors requiring treatment with radiotherapy are particularly prone to cognitive, behavioral and social problems. 